\title{
Graphene Nanoreactors: Photoreduction of Prussian Blue in Aqueous Solution
}

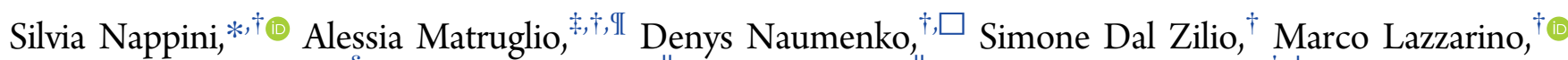 \\ Frank.M. F. De Groot, ${ }^{\S}{ }^{\circledR}$ Coskun Kocabas, ${ }^{\| @}$ Osman Balci, ${ }^{\|}$and Elena Magnano ${ }^{*}, \dagger, \perp$ \\ ${ }^{\dagger}$ IOM-CNR, Laboratorio TASC, S.S. 14 - km 163.5, 34149 Basovizza, Trieste, Italy \\ ${ }^{\ddagger}$ University of Trieste, Graduate School of Nanotechnology, Piazzale Europa 1, 34127 Trieste, Italy \\ ${ }^{\S}$ Inorganic Chemistry and Catalysis, Debye Institute for Nanomaterials Science, Utrecht University, Universiteitsweg 99, Utrecht, \\ Netherlands \\ "Department of Physics, Bilkent University, 06800 Ankara, Turkey \\ ${ }^{\perp}$ Department of Physics, University of Johannesburg, P.O. Box 524, Auckland Park, 2006 Johannesburg, South Africa
}

\section{Supporting Information}

\begin{abstract}
Prussian dyes are characterized by interesting photomagnetic properties due to the photoinduced electron transfer involved in the Fe oxidation and spin state changes. Ferromagnetic Prussian blue (PB) in contact with titanium dioxide $\left(\mathrm{TiO}_{2}\right)$ can be reduced to paramagnetic Prussian white (PW) upon UV band gap excitation of $\mathrm{TiO}_{2}$. This process is promoted by the presence of a hole scavenger, such as water, fundamental to ensure the overall charge balance and the continuity of the process. In order to clarify the photoinduced reduction mechanism and the role of water, an innovative system of graphene nanobubbles (GNBs) filled with a $\mathrm{PB}$ aqueous solution was developed, enabling the application of electron spectroscopies to the liquid phase, up to now limited by the vacuum required to overcome

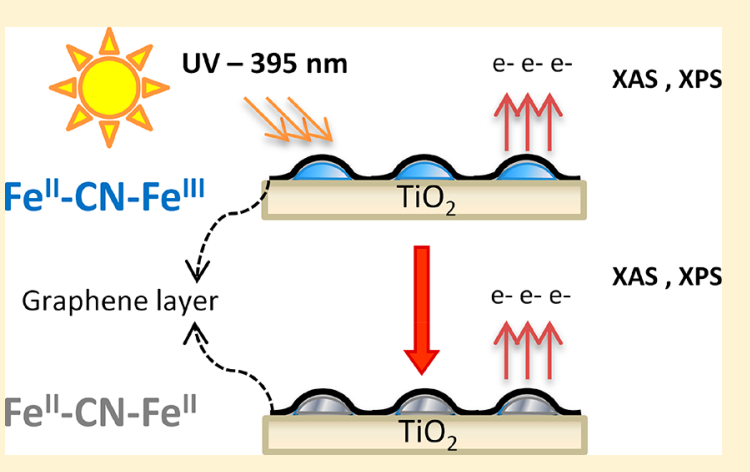
the short electron inelastic mean free path in dense medium. In this work GNBs formed on the photocatalytic substrate are able to act as "nanoreactors", and they can control and take part in the reaction. The evolution of $\mathrm{Fe} \mathrm{L}_{2,3}$ edge $\mathrm{X}$-ray absorption spectra measured in total electron yield through the graphene membrane revealed the electron reduction from $\mathrm{PB}$ ( $\mathrm{Fe} \mathrm{e}^{\mathrm{III}}-\mathrm{CN}-$ $\left.\mathrm{Fe}^{\mathrm{II}}\right)$ to $\mathrm{PW}\left(\mathrm{Fe}^{\mathrm{II}}-\mathrm{CN}-\mathrm{Fe}^{\mathrm{II}}\right)$ upon UV irradiation, shedding light on the photoinduced electron transfer mechanism in liquid phase. The results, confirmed also by Raman spectroscopy, unequivocally demonstrate that the reaction occurs preferentially in aqueous solution, where water acts as hole scavenger.
\end{abstract}

\section{INTRODUCTION}

Prussian blue (PB) and its analogues (ferrocyanides) are characterized by interesting photomagnetic, electrocatalytic, and optical properties that can be mainly attributed to photoinduced electron transfer processes capable of changing the oxidation and spin state of Fe inside the complex structure. Thanks to these characteristics and the capability to tune the magnetic and optical properties by external stimuli, PB analogues have found promising applications for memory photomagnetic devices, ${ }^{1,2}$ electroactive layers in electrochemistry, ${ }^{3,4}$ cathode materials for battery, ${ }^{5,6}$ and electrodes in biosensors. ${ }^{7-9}$ PB was also widely used as a pigment in different types of artwork of the 18th and 19th centuries, and, for this reason, it was the subject of several studies in the area of cultural heritage science to understand the fading process of the dye upon extended exposure to light. ${ }^{10,11}$

Prussian blue structure exists in two forms: "insoluble PB", $\mathrm{Fe}^{\mathrm{III}}{ }_{4}\left[\mathrm{Fe}^{\mathrm{II}}(\mathrm{CN})_{6}\right]_{3}$, and "soluble $\mathrm{PB}$ " or "Turnbull's blue", $\mathrm{KFe}^{\mathrm{III}}\left[\mathrm{Fe}^{\mathrm{II}}(\mathrm{CN})_{6}\right]^{10,12}$ Prussian blue color is due to the intervalence charge transfer between low-spin $\mathrm{Fe}^{\mathrm{II}}$ (LS-Fe ${ }^{\mathrm{II}}-$
C) and high-spin $\mathrm{Fe}^{\mathrm{III}}$ (HS-Fe $\left.\mathrm{HII}^{\mathrm{II}} \mathrm{N}\right)$ centers. Discoloration of the soluble ferromagnetic $\mathrm{PB}$ ionic species $\left[\mathrm{Fe}^{\mathrm{III}}\left(\mathrm{Fe}^{\mathrm{II}}(\mathrm{CN})_{6}\right)\right]^{+}$ under intense illumination is due to the reduction of $\mathrm{Fe}^{\mathrm{III}}-\mathrm{N}$ to $\mathrm{Fe}^{\mathrm{II}}-\mathrm{N}$ centers which leads to the formation of the paramagnetic colorless organometallic ion, well-known as Prussian white $(\mathrm{PW})$ with formula $\left[\mathrm{Fe}^{\mathrm{II}}\left(\mathrm{Fe}^{\mathrm{II}}(\mathrm{CN})_{6}\right)\right]^{2+}$.

Understanding the reduction mechanism of $\mathrm{PB}$ is important because it is the basic working principle of different biosensor and ion detection systems based on PB film electrodes. ${ }^{6,8,9,13-15}$ The photoinduced electron transfer is also responsible for the changes in the spin state of the metal centers of ferrocyanide compounds, leading to interesting photomagnetic properties which are widely used for several applications in the field of photomagnetism. ${ }^{2,16}$ For example, in Co-Fe Prussian blue, the electron excitation results in trapping the metastable high-spin state, ${ }^{16}$ showing that the efficiency of

Received: August 8, 2017

Revised: September 16, 2017

Published: September 19, 2017 
the photoinduced magnetization depends on a compromise between the number of excitable diamagnetic pairs and the amount of $\left[\mathrm{Fe}(\mathrm{CN})_{6}\right]$ vacancies. $^{17}$

Taguchi et al. ${ }^{18}$ have studied the photomagnetic effect in a composite system of semiconductive $\mathrm{CdS}$ and $\mathrm{PB}$ nanoparticles, evidencing the reduction of ferromagnetic $\mathrm{PB}$ to paramagnetic PW upon selective band gap excitation of CdS. Similarly, Yamamoto et al. ${ }^{1}$ have studied the photoinduced reduction of $\mathrm{PB}$ on titanium dioxide $\left(\mathrm{TiO}_{2}\right)$ nanosheets upon UV band gap excitation of $\mathrm{TiO}_{2}$ by FT-IR measurements, exploiting the $\mathrm{TiO}_{2}$ capability to reduce heavy metals and degrade organic compounds. ${ }^{19-21}$ It was observed that the electron transfer is promoted by the presence of water which acts as a scavenger of holes in the $\mathrm{TiO}_{2}$ valence band, enabling the reduction of $\mathrm{Fe}^{\mathrm{III}}$ to $\mathrm{Fe}^{\mathrm{II}}$.

In order to clarify the role of water and the mechanism of the photoinduced reduction of $\mathrm{PB}$ in an aqueous solution in contact with a $\mathrm{TiO}_{2}$ catalyst, we investigated by soft X-ray corelevel spectroscopies the electronic evolution of Fe core levels.

X-ray photoelectron spectroscopy (XPS) and X-ray absorption (XAS) are suitable techniques to study processes based on the transfer of electrons from a solid substrate to a solution or vice versa. The emitted photons and electrons with characteristic energies resulting from the direct excitation or relaxation of the core holes can be detected and analyzed to obtain information regarding the chemical environment, oxidation state, ligand field strength, and charge transfer effects of the investigated system. Unfortunately, soft X-ray propagation and photoelectron detection require the ultrahigh-vacuum (UHV) conditions, which hinder the application of soft X-ray techniques to the liquid-solid interfaces.

In the past decade substantial efforts have been devoted to the application of soft X-ray core-level spectroscopies to experiments under working conditions, such as ambient pressure photoelectron spectroscopy (AP-XPS) $)^{22-26}$ or the use of microfabricated liquid cells. ${ }^{27-34}$

Recentely, we have presented a novel, simple, and robust method to apply conventional electron spectroscopies to investigate the evolution of electrochemical or chemical reactions directly in their liquid environment. ${ }^{35}$ Graphene nanobubbles (GNBs) filled with the desired solution between a titanium dioxide $\mathrm{TiO}_{2}(100)$ rutile single crystal and a monolayer of graphene $(\mathrm{Gr})$ were used to follow the electronic evolution during the thermal-induced reduction of an aqueous solution of $\mathrm{FeCl}_{3}$ encased inside the GNBs.

The small thickness (only one atomic layer) and the high elasticity, mechanical strength, and impermeability of $\mathrm{Gr}$ provide the transparency to both photons and electrons required for the electronic characterization of the system placed under the Gr membrane. . $^{2,36,37}$

Here we did a step forward by using the GNB system for two purposes: it is a "sample holder" for electron spectroscopy from the liquid phase and a "reactor" that can control the process and take part in the reaction exploiting the photocatalytic properties of $\mathrm{TiO}_{2}{ }^{20,38-40}$

A complete in situ spectroscopic study of the photoreduction mechanism of $\mathrm{PB}$ (soluble form, $\mathrm{KFe}^{\mathrm{III}}\left[\mathrm{Fe}^{\mathrm{II}}(\mathrm{CN})_{6}\right]$ ) in aqueous solution encased in GNBs formed on a $\mathrm{TiO}_{2}$ catalyst is presented. The photoreduction was induced by using a laser at $395 \mathrm{~nm}$ of wavelength, corresponding to the band gap of rutile $(3.03 \mathrm{eV}),^{41}$ and the process was monitored after different UV exposure time. The reaction was followed in situ by core-level electron spectroscopy on the $\mathrm{BACH}$ beamline at Elettra synchrotron facility: the presence of the aqueous solution inside the GNBs was proved by measuring $\mathrm{O}$ 1s spectra by XPS, while the photoinduced electron transfer was examined by XAS at the $\mathrm{Fe}_{2,3}$ edge measured in total electron yield (TEY) through the $\mathrm{Gr}$ membrane. The photoinduced reduction of $\mathrm{Fe}$ centers was clearly evidenced by XAS changes upon UV irradiation, and the partial evolution of $\mathrm{PB}\left(\mathrm{Fe}^{\mathrm{III}}-\mathrm{CN}-\mathrm{Fe}^{\mathrm{II}}\right)$ to $\mathrm{PW}\left(\mathrm{Fe}^{\mathrm{II}}-\mathrm{CN}-\mathrm{Fe}^{\mathrm{II}}\right)$ was observed and confirmed by ligand field multiplet calculation. The results have definitely demonstrated that the reduction process induced by the electron transfer from the valence band to the conduction band of $\mathrm{TiO}_{2}$, and finally to $\mathrm{PB}$ molecules, requires the presence of water as hole scavenger. Raman spectroscopy in liquid phase was also performed to confirm the X-ray electron spectroscopy results.

\section{RESULTS AND DISCUSSION}

An array of GNBs filled with an aqueous solution of PB (10 $\mathrm{mM}$ ) was obtained by transferring a CVD grown Gr layer onto a $\mathrm{TiO}_{2}$ single crystal using a thermoplastic polymer as sacrificial layer (see Methods). The formation of GNBs was described in detail in our previous work ${ }^{35}$ and proved by several techniques, such as atomic force microscopy (AFM), Raman spectroscopy, XPS, and XAS. As previously described, the wettability of the bare $\mathrm{TiO}_{2}$ substrate, and thus the number of GNBs, was modulated by oxygen plasma and thermal treatments up to 700 ${ }^{\circ} \mathrm{C}$. ${ }^{42-44}$

Surface defects and adsorption of $\mathrm{OH}^{-}$groups on the crystal surface contribute to the formation of GNBs filled with an aqueous solution during the transfer protocol.

The presence of the aqueous solution inside GNBs was proved by measuring XPS $O$ is spectra before the UV irradiation and after $45 \mathrm{~min}$ of irradiation with a laser tuned at $395 \mathrm{~nm}$ of wavelength and $15 \mathrm{~mW}$ of power (Figure $1 \mathrm{a}$ ).

As previously reported for the GNBs filled with an aqueous solution, ${ }^{35}$ the $\mathrm{O} 1 \mathrm{~s}$ peaks can be deconvoluted in four components. The component at $533.4 \mathrm{eV}$ is related to liquid water and does not change after UV irradiation, demonstrating the sealing capability of the Gr membrane for the time scale of the experiment. ${ }^{27,28,45,46}$ The component at $532 \mathrm{eV}$ can be associated with $\mathrm{CO}-\mathrm{OH}$, due to atmospheric contamination or polymer residuals, also observed on $\mathrm{C} 1 \mathrm{~s}^{47}$ (Figure $1 \mathrm{~b}$ ). The component at $531.2 \mathrm{eV}$ can be related to hydroxyl radicals $(\mathrm{OH})$ at the $\mathrm{TiO}_{2}$ surface, and finally, the component at 530.2 $\mathrm{eV}$ is related to oxygen deficiencies ${ }^{48}$ or to bridging hydroxyls on the surface vacancies ${ }^{49}$ of bulk $\mathrm{TiO}_{2}$; this latter component is very low due to the dense media interposed between the $\mathrm{TiO}_{2}$ substrate and the Gr layer. XPS spectra of $\mathrm{C} 1 \mathrm{~s}$ before and after 45 min of irradiation were also measured to check the $\mathrm{Gr}$ condition after the UV treatment. The obtained spectra are shown in Figure $1 \mathrm{~b}$, evidencing that the UV irradiation does not change $\mathrm{Gr}$ components. Before and after irradiation, $\mathrm{C} 1 \mathrm{~s}$ spectra present a pronounced $\mathrm{sp}^{2}$ component at $284.6 \mathrm{eV}$ associated with high-quality $\mathrm{Gr}$, a sp ${ }^{3}$ component at $285.3 \mathrm{eV}$ associated with defects in the lattice and grain boundaries, and weak $\mathrm{C}-\mathrm{OH}$ and $\mathrm{O}-\mathrm{C}=\mathrm{O}$ components at 286.5 and $288.6 \mathrm{eV}$ due to atmospheric contamination and polymer residuals.

The irradiation does not introduce additional defects or damage into the Gr layer; indeed, a little decrease of the $\mathrm{O}-$ $\mathrm{C}=\mathrm{O}$ components is visible, indicating a cleaning effect of the UV laser in the presence of $\mathrm{TiO}_{2}$ substrate. ${ }^{50,51}$

XPS spectra of Fe $2 \mathrm{p}$ are not reported in the paper because the oxidation state of iron can be analyzed with a higher 

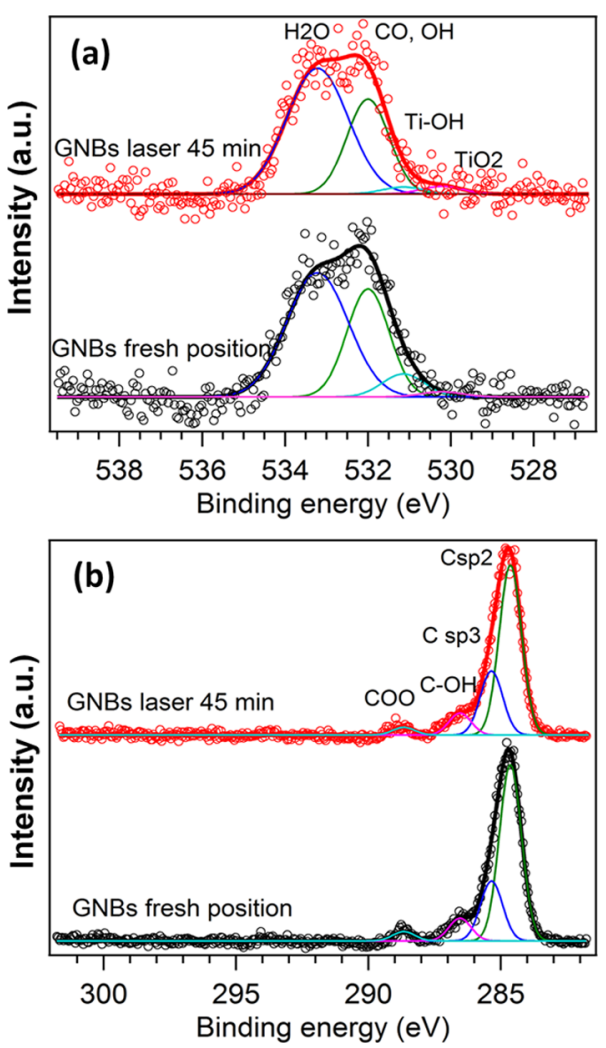

Figure 1. (a) XPS O 1s spectra of GNBs obtained before the UV irradiation (black curve) and after $45 \mathrm{~min}$ of irradiation (red curve) indicating the presence of water during the time scale of the experiment. (b) C 1s XPS spectra of GNBs before (black curve) and after $45 \mathrm{~min}$ of UV irradiation at $395 \mathrm{eV}$ (red curve) show no additional defects in the Gr layer induced by UV exposure.

accuracy by XAS measurements. Indeed, Prussian blue photoreduction was examined by XAS at the $\mathrm{Fe} \mathrm{L}_{2,3}$ edge measured in total electron yield (TEY) exploiting the high electrical conductivity of the $\mathrm{Gr} /$ liquid interface which enabled the measurement of spectra with unprecedented high signal/ noise ratio. $\mathrm{Fe} \mathrm{L}_{2,3}$ edge XAS corresponds to $2 \mathrm{p} \rightarrow 3 \mathrm{~d}$ transition and provides a direct and sensitive measure of the fraction of $\mathrm{Fe}$ $3 \mathrm{~d}$ orbitals hybridized with ligand $2 \mathrm{p}$ as a function of the metal valence and spin state. The sensitivity of the XAS line shape of $\mathrm{Fe}$ in a particular ligand field allows a quantitative analysis of the valences of $\mathrm{Fe}$ atoms.

Indeed, XAS spectra can be accurately modeled by ligand field multiplet calculation enabling a direct assignment of each spectroscopic feature to a specific oxidation and spin state of $\mathrm{Fe}$ atoms in PB. In Figure 2a XAS spectra measured at different intervals of UV exposure time are reported: before the irradiation (black line), after $20 \mathrm{~min}$ (green line), after 40 min (blue line), and after $70 \mathrm{~min}$ (red line) of irradiation. Before irradiation the $\mathrm{Fe} \mathrm{L}_{2,3}$-edge XAS spectrum has the typical line shape expected for a mixed iron complex system such as $\mathrm{PB},{ }^{6,52} \mathrm{KFe}^{\mathrm{III}}\left[\mathrm{Fe}^{\mathrm{II}}(\mathrm{CN})_{6}\right]$, which is a mixture of lowspin $\mathrm{Fe}^{\mathrm{II}}$ centers $\left(\mathrm{LS}-\mathrm{Fe}^{\mathrm{II}}-\mathrm{C}\right.$ ) and high-spin $\mathrm{Fe}^{\mathrm{III}}$ centers (HS$\left.\mathrm{Fe}^{\mathrm{III}}-\mathrm{N}\right)$. Fe L-edge XAS spectra clearly show the progressive formation of reduced $\mathrm{Fe}$ species ${ }^{6}$ as a function of the UV exposure time: $\mathrm{Fe}^{\mathrm{III}}-\mathrm{CN}-\mathrm{Fe}^{\mathrm{II}}$ evolves gradually to $\mathrm{Fe}^{\mathrm{II}}-\mathrm{CN}-$ $\mathrm{Fe}^{\mathrm{II}}$, as shown by the intensity increase of the peaks at 707.15 and $720.3 \mathrm{eV}$ as indicated in Figure $2 \mathrm{a}$. In order to prove the reduction of $\mathrm{HS}-\mathrm{Fe}^{\mathrm{III}}-\mathrm{N}$ to $\mathrm{HS}-\mathrm{Fe}^{\mathrm{II}}-\mathrm{N}$ centers, XAS spectra were simulated by linear combination of the calculated spectral
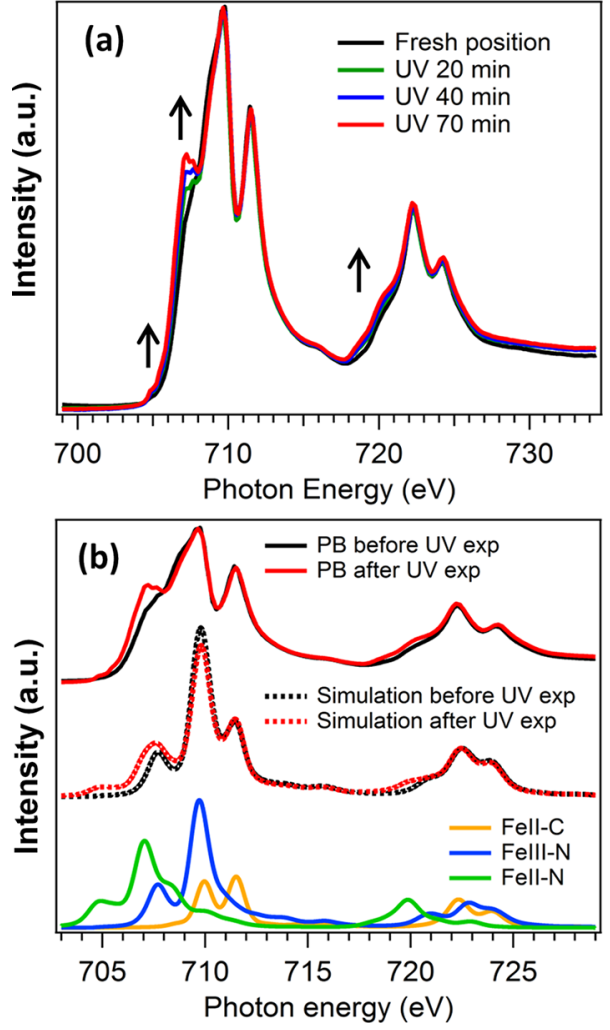

Figure 2. (a) Experimental XAS spectra at $\mathrm{Fe}_{2,3}$ edge measured before (black line) and after $20 \mathrm{~min}$ (green line), $40 \mathrm{~min}$ (blue line), and $70 \mathrm{~min}$ of UV irradiation (red line) of an aqueous solution of $\mathrm{PB}$. (b) From top to bottom: experimental $\mathrm{Fe}_{2,3}$ edge XAS spectra of $\mathrm{PB}$ before (black solid line) and after $70 \mathrm{~min}$ of UV irradiaton (red solid line); calculated spectra of PB before (black dashed line) and after laser exposure (red dashed line); simulated spectroscopic components of $\mathrm{Fe}^{\mathrm{II}}-\mathrm{C}$ (yellow line), $\mathrm{Fe}^{\mathrm{II}}-\mathrm{N}$ (green line), and $\mathrm{Fe}^{\mathrm{III}}-\mathrm{N}$ (blue line) atoms coordinated to cyano groups. The linear combination of the simulated spectral features ( $\mathrm{PB}$ calculated spectra) indicates that $30 \%$ of $\mathrm{Fe}^{\mathrm{III}}-\mathrm{N}$ atoms are reduced to $\mathrm{Fe}^{\mathrm{II}}-\mathrm{N}$ species after $70 \mathrm{~min}$ of $\mathrm{UV}$ irradiation.

components present in $\mathrm{PB}$ molecules before and after UV exposure. The simulated curves of each spectroscopic feature (LS-Fe ${ }^{\mathrm{II}}-\mathrm{C}, \mathrm{HS}-\mathrm{Fe}^{\mathrm{III}}-\mathrm{N}$, and $\mathrm{HS}-\mathrm{Fe}^{\mathrm{II}}-\mathrm{N}$ ) were calculated with the ligand field multiplet approach (see Methods), and their linear combination was optimized to reproduce the experimental line shape of PB spectra reported in Figure $2 \mathrm{~b}$.

The calculations of the single spectral features were optimized by following those developed by Wang et al. $^{6}$ and Hocking et al. ${ }^{52}$

The hopping parameters and back-bonding configuration energies were adjusted to reproduce the spectral components found in the literature ${ }^{6}$ and to model as best as possible the energy splittings of our experimental XAS spectra. The parameters optimized for the calculations are reported in Table 1 in the Methods section. As expected, a linear combination of $50 \%$ LS$-\mathrm{Fe}^{\mathrm{II}}-\mathrm{C}$ and $50 \% \mathrm{HS}-\mathrm{Fe}^{\mathrm{III}}-\mathrm{N}$ reproduces quite well the line shape of the XAS spectrum of fresh $\mathrm{PB}$. The best simulation of the XAS spectrum of $\mathrm{PB}$ irradiated $70 \mathrm{~min}$ with UV light was achieved by a linear combination of $15 \% \mathrm{HS}-\mathrm{Fe}^{\mathrm{II}}-\mathrm{N}, 35 \% \mathrm{HS}-\mathrm{Fe}^{\mathrm{III}}-\mathrm{N}$, and $50 \%$ $\mathrm{LS}-\mathrm{Fe}^{\mathrm{II}}-\mathrm{C}$. Indeed, the calculation provides a direct verification that about $30 \%$ of $\mathrm{Fe}^{\mathrm{III}}-\mathrm{N}$ atoms were reduced to $\mathrm{Fe}^{\mathrm{II}}-\mathrm{N}$ species upon $70 \mathrm{~min}$ of UV irradiation. Despite the good 
Table 1. Ligand Field Multiplet Parameters Used for Simulations of Prussian Dye Components

\begin{tabular}{|c|c|c|c|c|c|c|c|c|c|}
\hline \multirow[b]{2}{*}{ component } & \multicolumn{5}{|c|}{ configuration energies } & \multicolumn{4}{|c|}{ mixing parameters } \\
\hline & $10 \mathrm{Dq}$ & $\mathrm{E}_{\mathrm{G} 2}$ & $\mathrm{E}_{\mathrm{F} 2}$ & $\mathrm{E}_{\mathrm{G} 3}$ & $\mathrm{E}_{\mathrm{F} 3}$ & $\sigma$-back bonding & $\pi$-back bonding & $\sigma$-bonding & $\pi$-bonding \\
\hline $\mathrm{Fe}^{\mathrm{II}}-\mathrm{C}$ & 4.6 & 3.0 & 2.5 & -2.9 & -0.9 & 1.1 & 1.85 & 2.2 & 0.0 \\
\hline $\mathrm{Fe}^{\mathrm{III}}-\mathrm{N}$ & 1.6 & 1.0 & 0.5 & -2.0 & 1.0 & 0.0 & 0.0 & 1.7 & 0.9 \\
\hline $\mathrm{Fe}^{\mathrm{II}}-\mathrm{N}$ & 1.7 & - & - & - & - & - & - & - & - \\
\hline
\end{tabular}

agreement, the calculated XAS are not perfectly superimposed to the experimental ones. The difference between theoretical and experimental curves may be related to the presence of negligible amount of $\mathrm{K}_{3}\left[\mathrm{Fe}(\mathrm{CN})_{6}\right]$ and $\mathrm{FeCl}_{2}$ residuals from the $\mathrm{PB}$ preparation, which were not accounted for in the simulation. For sake of clarity, the calculated spectroscopic components $\mathrm{Fe}^{\mathrm{III}}-\mathrm{C}$ and $\mathrm{Fe}^{\mathrm{II}}-\mathrm{Cl}$ ascribed to the two $\mathrm{PB}$ precursors are reported in Figure S-3 in the Supporting Information.

In order to be sure that the Fe reduction is due exclusively to the UV irradiation in our experimental conditions, but not to the possible damage induced by the X-rays, ${ }^{4,53}$ the synchrotron light contribution was evaluated as well. A second fresh sample of GNBs filled with a $10 \mathrm{mM}$ solution of PB was used as reference and exposed only to the synchrotron light for $45 \mathrm{~min}$ adopting the same experimental conditions used for XAS measurements (photon energy and beam flux) without laser irradiation. Figure 3 a reports the comparison between the spectrum measured before irradiation and the spectra collected after exposure to the UV laser for $45 \mathrm{~min}$ (bottom spectra) and to X-rays for $45 \mathrm{~min}$ (top spectra).

As visible in Figure 3 a, upon UV irradiation the intensity of peaks at 707.15 and $720.3 \mathrm{eV}$ increases, and the spectrum line shape approaches the one reported for reduced $\mathrm{Fe}^{\mathrm{II}}-\mathrm{CN}-\mathrm{Fe}^{\mathrm{II}}$ species typical of PW (as described before). ${ }^{6,52}$ In the case of the sole X-ray irradiation, no evident change in the $\mathrm{Fe}_{2,3}$ edge is visible after $45 \mathrm{~min}$ of exposure, confirming that the main factor responsible for the Fe reduction is the UV light exposure, whose energy corresponds to the band gap of $\mathrm{TiO}_{2}$.

The role of the aqueous environment was investigated as well to understand if the presence of water is necessary for the photoreduction process. $\mathrm{Fe} \mathrm{L}_{2,3}$ edge XAS spectra of $\mathrm{PB}$ solution encased inside GNBs were compared with those acquired on a dry sample before and after laser exposure. The dry $\mathrm{PB}$ sample was prepared by drop-casting method on $\mathrm{TiO}_{2}$ rutile single crystal. Both samples were irradiated with the same UV laser for $20 \mathrm{~min}$, a sufficient time to see Fe reduction (as previously observed in Figure 2 a). The obtained results are shown in Figure $3 \mathrm{~b}$.

As widely discussed above, the PB solution inside GNBs on $\mathrm{TiO}_{2}$ shows the clear sign of $\mathrm{Fe}$ reduction upon UV irradiation. On the contrary, the dry $\mathrm{PB}$ sample drop casted on $\mathrm{TiO}_{2}$ does not show any feature of reduced Fe. These results indicate that the water environment is a fundamental requirement for the photoinduced reduction of $\mathrm{PB}$, and the GNB approach ensures this basic condition.

In light of the observed results, it is clear that the gradual photoinduced reduction of $\mathrm{Fe}^{\mathrm{III}}-\mathrm{CN}-\mathrm{Fe}^{\mathrm{II}}$ species (PB) to $\mathrm{Fe}^{\mathrm{II}}-\mathrm{CN}-\mathrm{Fe}^{\mathrm{II}}$ species (PW) occurs preferentially under the $395 \mathrm{~nm}$ laser excitation energy and in the presence of an aqueous environment. Indeed, upon UV band gap excitation of rutile $\left(E_{\mathrm{g}}=3.03 \mathrm{eV}\right)$, the electrons of the valence band are photoexcited to the conduction band of $\mathrm{TiO}_{2}$, generating both holes and electrons in the valence and conduction bands, respectively.
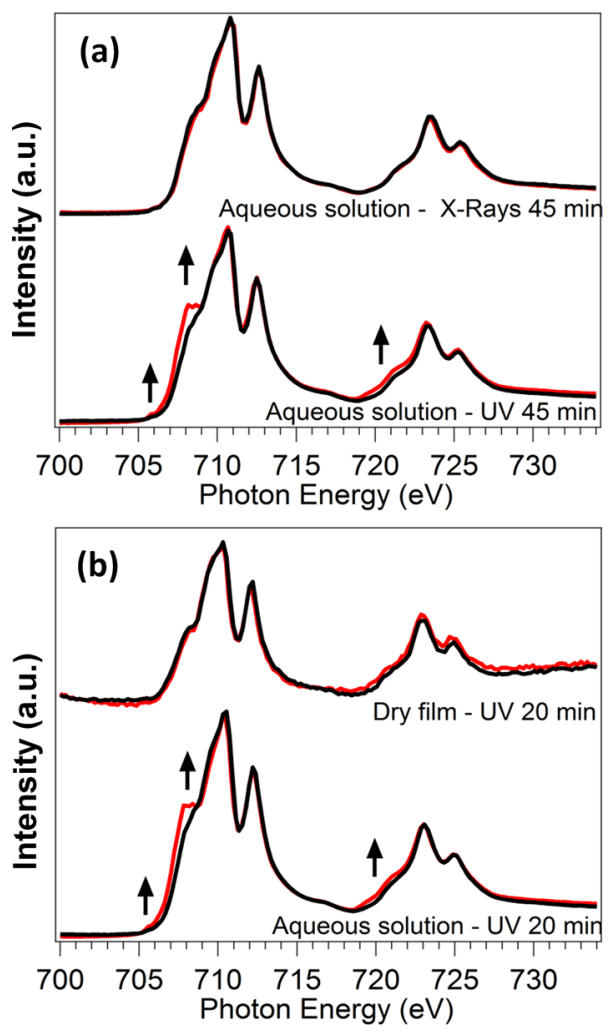

Figure 3. (a) XAS Fe $\mathrm{L}_{2,3}$ edge spectra of an aqueous solution of $\mathrm{PB}$ in GNBs exposed for $45 \mathrm{~min}$ to UV irradiation (red curve, bottom spectra) and for $45 \mathrm{~min}$ to X-rays irradiation (red curve, top spectra). (b) XAS Fe $\mathrm{L}_{2,3}$ edge spectra measured after $20 \mathrm{~min}$ of UV exposure of the following: a $\mathrm{PB}$ aqueous solution in $\mathrm{GNBs} / \mathrm{TiO}_{2}$ (red curve, bottom spectra) and a $\mathrm{PB}$ dry film on $\mathrm{TiO}_{2}$ (red curve, top spectra). The black spectra are measured before the irradiation. The photoreduction of $\mathrm{Fe}$ occurs only under UV light and in wet environment. No evident photoinduced effects are visible under X-rays exposure and in the absence of water.

The role of water is extremely important to allow the evolution of the reaction; in fact, water acts as a scavenger and reduces the generated holes in the valence band, preventing the electrons excited to the conduction band from being easily recombined with holes. ${ }^{54}$

These conditions are required to ensure a continuous supply of photoexcited electrons to the conduction band of $\mathrm{TiO}_{2}$, which can be injected into the electronic states of $\mathrm{PB}$ to reduce $\mathrm{Fe}^{\mathrm{III}}-\mathrm{N}$ to $\mathrm{Fe}^{\mathrm{II}}-\mathrm{N}$ atoms. The remaining holes in the valence band of $\mathrm{TiO}_{2}$ oxidize water molecules to produce protons, which are used to ensure the charge balance of the partial reduced dye. ${ }^{1}$ The proposed photoreduction mechanism is reported in Figure 4.

The process was further studied by Raman spectroscopy in liquid phase. Raman spectra of GNB samples (black and red lines in Figure 5 a, corresponding to fresh and UV irradiated samples, respectively) show the characteristic features of $\mathrm{Gr}$ at 


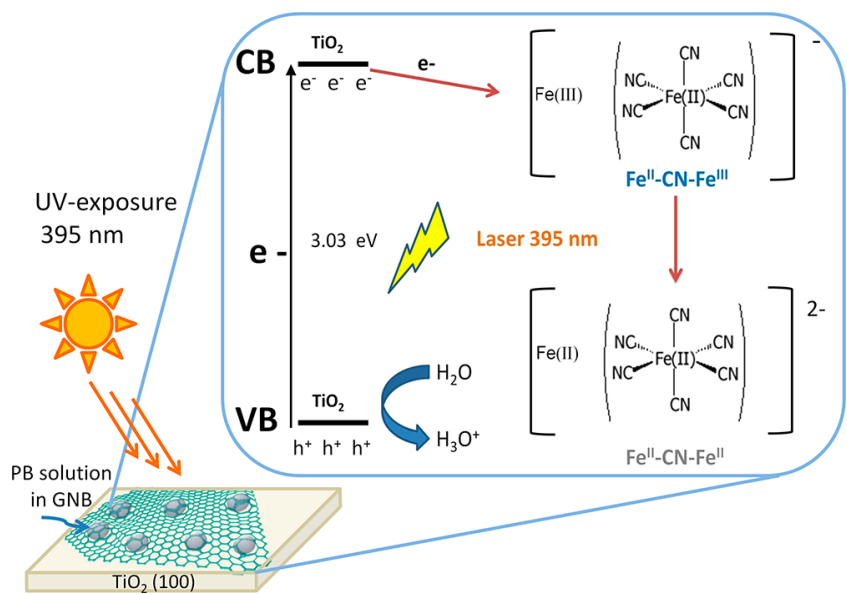

Figure 4. Proposed photoreduction mechanism of PB: upon UV band gap excitation of $\mathrm{TiO}_{2}\left(E_{\mathrm{g}}=3.03 \mathrm{eV}\right)$ the electrons $\left(\mathrm{e}^{-}\right)$of the valence band $(\mathrm{VB})$ are promoted to the conduction band (CB) of $\mathrm{TiO}_{2}$, generating both holes $\left(\mathrm{h}^{+}\right)$and $\mathrm{e}^{-}$in the $\mathrm{VB}$ and $\mathrm{CB}$, respectively. $\mathrm{H}_{2} \mathrm{O}$ acts as a scavenger to reduce the generated $h^{+}$in the VB, preventing the $\mathrm{e}^{-}$of $\mathrm{CB}$ from being easily recombined with $\mathrm{h}^{+}$. The photoexcited $\mathrm{e}^{-}$can be injected into the electronic states of $\mathrm{PB}$ to reduce $\mathrm{Fe}^{\mathrm{III}}-\mathrm{N}$ to $\mathrm{Fe}^{\mathrm{II}}-\mathrm{N}$ atoms. The remaining $\mathrm{h}^{+}$in the $\mathrm{VB}$ of $\mathrm{TiO}_{2}$ are used to oxidize the $\mathrm{H}_{2} \mathrm{O}$ molecules and produce $\mathrm{H}_{3} \mathrm{O}^{+}$ions to ensure the charge balance of the reduced $\mathrm{PB}$.

1590 and $2695 \mathrm{~cm}^{-1}$ which are ascribed to $\mathrm{G}$ and $2 \mathrm{D}$ peaks, respectively. ${ }^{55,56}$

$\mathrm{G}$ and $2 \mathrm{D}$ bands are not affected by UV illumination, and no defects are introduced within the exposure time, as also evident in Figure S-4 in the Supporting Information. Other features at $443.4 \mathrm{~cm}^{-1}$ ( $\mathrm{E}_{\mathrm{g}}$ rutile mode) and $610.8 \mathrm{~cm}^{-1}$ ( $\mathrm{A}_{\mathrm{g}}$ rutile mode) are ascribed to $\mathrm{TiO}_{2}$ substrate, while the small components between 200 and $700 \mathrm{~cm}^{-1}$ can be assigned to $\mathrm{Fe}-\mathrm{C}$ and $\mathrm{Fe}-\mathrm{N}$ stretching and $\mathrm{Fe}-\mathrm{C}-\mathrm{N}$ and $\mathrm{Fe}-\mathrm{N}-\mathrm{C}$ bending modes ${ }^{11,57}$ typical of ferrocyanides, which are visible also on dry $\mathrm{PB}$ (blue line).

Finally, the characteristic $\mathrm{C} \equiv \mathrm{N}$ vibrational peak around $2162 \mathrm{~cm}^{-1}$ is ascribed to the $\mathrm{Fe}^{\mathrm{II}}-\mathrm{C} \equiv \mathrm{N}-\mathrm{Fe}^{\mathrm{III}} \mathrm{A}_{\mathrm{g}}$ (symmetric) stretching mode of $\mathrm{PB}{ }^{10,11}$

An expanded view of the $\mathrm{C} \equiv \mathrm{N}$ vibrational component is presented in Figure $5 \mathrm{~b}$, and all the spectra have been normalized to this peak for a comparative analysis.

On dry PB sample on glass (blue line), this mode is observed at $2160 \mathrm{~cm}^{-1}$, resulting downshifted by $2-3 \mathrm{~cm}^{-1}$ with respect to PB solution in GNBs (red and black lines). This shift is most likely due to the presence of water or $\mathrm{OH}^{-}$ions, which can play an important role in the frequency shift of $A_{g}$ stretching mode. This finding proves again the presence of aqueous solution in GNBs. The weak peak around $2098 \mathrm{~cm}^{-1}$ is attributed to the $\mathrm{E}_{\mathrm{g}}$ mode (asymmetric) of the $\mathrm{Fe}^{\mathrm{II}}-\mathrm{C} \equiv \mathrm{N}-\mathrm{Fe}^{\mathrm{III}}$ stretching vibration, ${ }^{11}$ and its intensity remains unchanged upon UV illumination. Finally, the relative intensity of the shoulder at $2127 \mathrm{~cm}^{-1}$, corresponding to $\mathrm{Fe}^{\mathrm{II}}-\mathrm{C} \equiv \mathrm{N}-\mathrm{Fe}^{\mathrm{II}}$ stretching mode of $\mathrm{CN}$ group coordinated to two $\mathrm{Fe}^{\mathrm{II}}$ atoms, grows after $15 \mathrm{~h}$ of UV illumination (red line).

The higher intensity of this feature upon UV exposure proves an increase of reduced $\mathrm{Fe}^{\mathrm{II}}$ cations, confirming the partial photoreduction of $\mathrm{PB}$ to $\mathrm{PW}$ in aqueous solution on a $\mathrm{TiO}_{2}$ substrate.
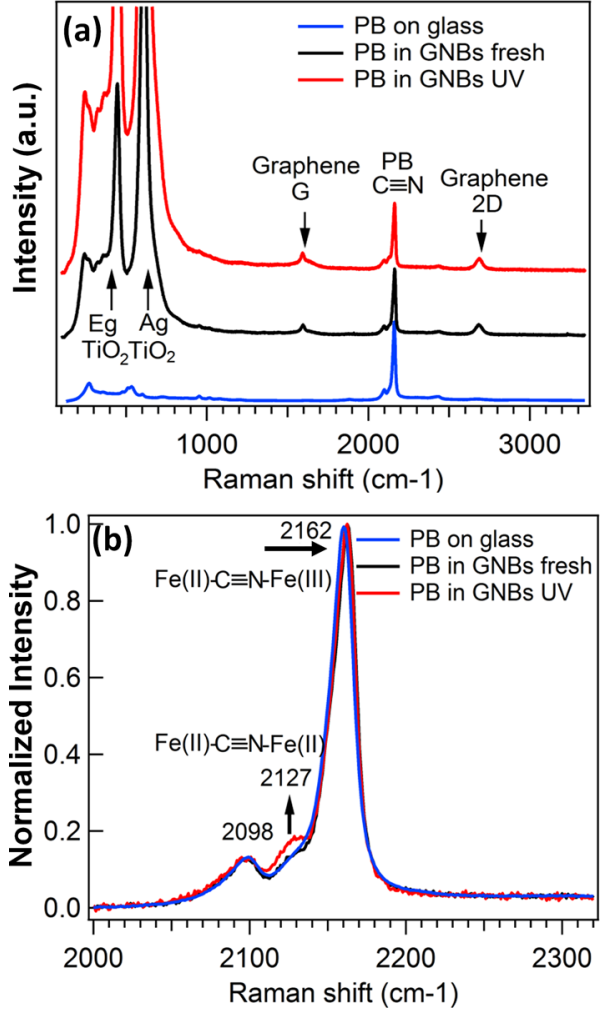

Figure 5. (a) Raman spectra of dry PB on glass (blue line), freshly prepared GNBs filled with $\mathrm{PB}$ aqueous solution on $\mathrm{TiO}_{2}$ (black line) and after $15 \mathrm{~h}$ of UV exposure (red line). (b) Zoomed region of Raman $\mathrm{C} \equiv \mathrm{N}$ stretching mode of $\mathrm{PB}$. The vibrational peak around $2162 \mathrm{~cm}^{-1}$ on PB solution in GNBs (black and red lines) results upshifted by $2-3 \mathrm{~cm}^{-1}$ with respect to dry $\mathrm{PB}$ (blue line) due to the presence of water. The intensity of the $\mathrm{Fe}^{\mathrm{II}}-\mathrm{C} \equiv \mathrm{N}-\mathrm{Fe}^{\mathrm{II}}$ stretching mode component at $2127 \mathrm{~cm}^{-1}$ grows after $15 \mathrm{~h}$ of $\mathrm{UV}$ illumination (red line), while the peak around $2098 \mathrm{~cm}^{-1}$ of the $\mathrm{Fe}^{\mathrm{II}}-\mathrm{C} \equiv \mathrm{N}-\mathrm{Fe}^{\mathrm{III}}$ stretching vibration remains unchanged. The higher intensity of the $\mathrm{Fe}^{\mathrm{II}}-\mathrm{C} \equiv \mathrm{N}-\mathrm{Fe}^{\mathrm{II}}$ feature upon $\mathrm{UV}$ exposure proves the formation of new $\mathrm{Fe}^{\mathrm{II}}$ species, thus the photoreduction of $\mathrm{PB}$ in aqueous solution on a $\mathrm{TiO}_{2}$ substrate.

\section{METHODS}

Prussian Blue Solution. An aqueous solution of the soluble form of $\mathrm{PB}(100 \mathrm{mM})$ was prepared by mixing at room temperature equal volumes of $100 \mathrm{mM}$ solutions of $\mathrm{K}_{3}[\mathrm{Fe}-$ $\left.(\mathrm{CN})_{6}\right]$ (potassium ferri-cyanide, Sigma-Aldrich) and $\mathrm{FeCl}_{2}$. $4 \mathrm{H}_{2} \mathrm{O}$ (iron(II) chloride tetrahydrate, Sigma-Aldrich). The reaction is described by the chemical eq 1 :

$$
\mathrm{Fe}^{\mathrm{II}} \mathrm{Cl}_{2}+\mathrm{K}_{3}\left[\mathrm{Fe}^{\mathrm{III}}(\mathrm{CN})_{6}\right] \rightarrow \mathrm{KFe}^{\mathrm{III}}\left[\mathrm{Fe}^{\mathrm{II}}(\mathrm{CN})_{6}\right]+2 \mathrm{KCl}
$$

The final PB solution was diluted 10 times to avoid the formation of aggregates, but the concentration of $\mathrm{Fe}$ was chosen high enough to have a good XAS signal. A picture of the starting and the final solutions of $\mathrm{K}_{3}\left[\mathrm{Fe}(\mathrm{CN})_{6}\right]$ and $\mathrm{KFe}^{\mathrm{III}}\left[\mathrm{Fe}^{\mathrm{II}}(\mathrm{CN})_{6}\right]$ is shown in Figure S-1 in the Supporting Information.

Graphene Nanobubbles Fabrication. The Gr layers were provided by the Department of Physics of Bilkent University in Ankara, Turkey. Graphene was synthesized on copper foils by chemical vapor deposition (CVD) according to the procedure described elsewhere. ${ }^{58,59}$ The copper foils were placed in a quartz chamber and heated to $1000{ }^{\circ} \mathrm{C}$ under flow of hydrogen 
and argon gases. After the annealing process, methane gas with a flow rate of $15 \mathrm{sccm}$ (standard cubic centimeters per minute) was sent to the chamber for $20 \mathrm{~min}$. The chamber pressure was kept at 5 Torr during the growth. The growth was terminated by stopping the flow of methane gas, and then the chamber was cooled back to room temperature. The high quality of as-grown Gr was proved by SEM and Raman spectroscopy at IOM-CNR laboratory (see S-2 in the Supporting Information). For the samples preparation, the same procedure described in our previous work was adopted: ${ }^{35}$ a layer of $250 \mathrm{~nm}$ of $\mathrm{mr}-\mathrm{I} 7020$ (Micro Resist technology $\mathrm{GmbH}$ ) was spin-coated on $\mathrm{Gr}$, and then $\mathrm{Cu}$ foil was etched overnight in $\mathrm{FeCl}_{3}(1.6 \mathrm{M})$. After the rinse in deionized water, the $\mathrm{mr}-\mathrm{I} / \mathrm{Gr} / \mathrm{Cu}$ membrane was put floating in the $\mathrm{PB}$ solution and directly fished with a $\mathrm{TiO}_{2}(100)$ rutile single-crystal substrate, allowing the formation of GNBs. Dry samples were also prepared by drop-casting method in order to analyze the role of water.

Electron Spectroscopies. XPS and XAS measurements of the samples were carried out on the CNR BACH beamline at Elettra Sincrotrone in Trieste (Italy). ${ }^{60,61}$

XPS spectra of $\mathrm{C} 1 \mathrm{~s}$ and $\mathrm{O} 1 \mathrm{~s}$ core levels were recorded at $596 \mathrm{eV}$ of photon energy. A VG-Scienta R3000 hemispherical analyzer, ${ }^{62}$ working with an overall energy resolution of $0.2 \mathrm{eV}$, was used. All spectra were fitted by a Gaussian function after the prior subtraction of a Shirley background to account for the inelastic photoelectrons. XAS spectra at the $\mathrm{L}_{2,3}$ edge of $\mathrm{Fe}$ before and after the UV laser $(15 \mathrm{~mW}, 395 \mathrm{~nm})$ exposure were measured in TEY collecting the current flowing through the $\mathrm{Gr}$ membrane.

The laser (PS-LBX, $395 \mathrm{~nm}, 15 \mathrm{~mW}$, Oxxius) was placed on a laser board, and the light was impinged on the samples through an optical window mounted on the experimental chamber of $\mathrm{BACH}$ beamline at $22.5^{\circ}$ from the sample surface normal.

Raman Spectroscopy. Raman measurements were performed in the reflection geometry on an inverted optical microscope (Axiovert 200, Zeiss) coupled with a $750 \mathrm{~mm}$ long spectrometer (Shamrock SR-750, Andor Technology plc). CW laser with the excitation wavelength of $532 \mathrm{~nm}$ (Cobolt Samba, $50 \mathrm{~mW}$, bandwidth $1 \mathrm{MHz}$ ) was used as an excitation source. A laser beam was reflected by $45^{\circ}$ oriented beamsplitter $(532 \mathrm{~nm}$ RazorEdge Dichroic), directed to the inverted microscope and then focused on the mounted sample by $100 \times$ air objective (NA 0.8, EC Epiplan), resulting in a diameter of laser spot of around $0.35 \mu \mathrm{m}$. The laser power on the sample was controlled by variable neutral density filter (NDC-50C-4M, Thorlabs) and kept at $1 \mathrm{~mW}$ to avoid temperature-induced effects. The Raman scattered light was collected by the same objective and sent to the spectrometer by the same optical path, dispersed by a diffractive grating of 600 lines $\mathrm{mm}^{-1}$, and finally analyzed using TE-cooled EMCCD (Newton DU971-UVB, Andor Technology plc). The Rayleigh scattered light was blocked by the longpass edge filter (532 nm RazorEdge) at the entrance of spectrometer. The acquisition time in all experiments was $60 \mathrm{~s}$.

Simulations. Ligand field multiplet simulations were carried out exploiting the multiplet model implemented by Thole ${ }^{63}$ and Cowan ${ }^{64}$ and by using the CTM4XAS 5.5 program developed by Stavitski and de Groot ${ }^{65}$ which includes spinorbit coupling, Coulomb interactions, and crystal field effects. Atomic Slater integrals were used, and all spectra were broadened by a Lorentzian with a half-width of $0.2(0.3) \mathrm{eV}$ and by a Gaussian with a sigma value of $0.3 \mathrm{eV}$. Metal-to-ligand and ligand-to-metal charge transfer (MLCT and LMCT) were considered as a linear combination of three $\mathrm{Fe} 3 \mathrm{~d}$ configurations: $3 \mathrm{~d}^{N-1} \mathrm{~L}, 3 \mathrm{~d}^{N}$, and $3 \mathrm{~d}^{N+1} \mathrm{H}$, where $\mathrm{L}$ is a ligand orbital and $\mathrm{H}$ is a hole in another ligand orbital. The configuration energies of different $\mathrm{Fe}$ ground states were defined by $\mathrm{E}_{\mathrm{G} 2}$ and $\mathrm{E}_{\mathrm{G} 3}$ parameters, which are the energy differences of all the averaged configuration energies of $\mathrm{Fe}$ with the nominal electron number $\left(3 \mathrm{~d}^{N}\right)$, without one electron transferred to cyano $\mathrm{CN}$-group $\left(3 \mathrm{~d}^{N-1}\right)$ and with an extra electron transferred from CN-group $\left(3 \mathrm{~d}^{N+1}\right)$. The configuration energies of different $\mathrm{Fe}$ final states (core hole states), $\mathrm{E}_{\mathrm{F} 2}$ and $\mathrm{E}_{\mathrm{F} 3}$, were defined identically as the ground states $\mathrm{E}_{\mathrm{G} 2}$ and $\mathrm{E}_{\mathrm{G} 3}{ }^{6,52}$ The effects of $\sigma$ - and $\pi$-donation from water to Fe ions were not accounted for in these simulations.

The parameters used to simulate $\mathrm{Fe}^{\mathrm{II}}-\mathrm{C}, \mathrm{Fe}^{\mathrm{III}}-\mathrm{N}$, and $\mathrm{Fe}^{\mathrm{II}}-$ $\mathrm{N}$ components expected in $\mathrm{PB}$ and $\mathrm{PW}$ species are reported in Table 1. The best simulation of high-spin state $\mathrm{Fe}^{\mathrm{II}}-\mathrm{N}$ was achieved using a single configuration $\left(3 \mathrm{~d}^{N}\right)$ and without the use of mixing parameters.

Since the presence of additional components due to $\mathrm{PB}$ precursors cannot be completely excluded, extra components of $\mathrm{Fe}^{\mathrm{III}}-\mathrm{C}$ and $\mathrm{Fe}^{\mathrm{II}}-\mathrm{Cl}$ ascribed to $\mathrm{FeCl}_{2}$ and $\mathrm{K}_{3}\left[\mathrm{Fe}^{\mathrm{III}}(\mathrm{CN})_{6}\right]$ were simulated and reported in Figure $S-3$ together with the corresponding parameters in Table S-1 (Supporting Information).

\section{CONCLUSION}

This work sheds light on the photoinduced reduction mechanism of a PB dye in aqueous solution in the presence of $\mathrm{TiO}_{2}$ catalyst. The role of the solvent was analyzed, and the photochemical reaction was monitored for the first time by using conventional electron spectroscopy methods in UHV conditions. GNBs were employed to follow in situ and in operando the evolution of the electronic properties of the sample in liquid environment. Thanks to the possibility of filling "quasi" transparent to photons and electrons GNBs with liquids, the well-known UV-induced reduction of an aqueous solution of $\mathrm{PB}$ catalyzed by band gap excitation of $\mathrm{TiO}_{2}$ was followed by XAS measurements.

XAS spectra at the $\mathrm{L}_{2,3}$ edge of $\mathrm{Fe}$ showed the gradual evolution from $\mathrm{PB}\left(\mathrm{Fe}^{\mathrm{III}}-\mathrm{CN}-\mathrm{Fe}^{\mathrm{II}}\right)$ to $\mathrm{PW}\left(\mathrm{Fe}^{\mathrm{II}}-\mathrm{CN}-\mathrm{Fe}^{\mathrm{II}}\right)$, confirmed also by ligand field multiplet calculation, and $\mathrm{O}$ 1s XPS measurements proved the presence of water inside GNBs before and after UV irradiation.

Our data suggest that photoexcited electrons promoted to the conduction band of $\mathrm{TiO}_{2}$ are used by $\mathrm{PB}$ to reduce HS$\mathrm{Fe}^{\mathrm{III}}-\mathrm{N}$ to $\mathrm{HS}-\mathrm{Fe}^{\mathrm{II}}-\mathrm{N}$ species. The results clearly demonstrate that this process requires the presence of water as scavenger to reduce the generated holes in the valence band of rutile; otherwise, the excited electrons could be easily recombined with holes, stopping the reduction of $\mathrm{Fe}$ species. The results were further confirmed by Raman measurements of $\mathrm{PB}$ solution in GNBs, evidencing changes of the $\mathrm{C} \equiv \mathrm{N}$ vibrational stretching modes as a function of the $\mathrm{Fe}$ oxidation state.

In conclusion, thanks to the GNB approach, the mechanism of photocatalytic reduction of $\mathrm{PB}$ in aqueous solution was finally investigated by electron spectroscopy. This paper proves again the robustness and reliability of GNBs as a valuable method to study the evolution of a large variety of physicalchemical processes in liquid phase, with a particular attention to liquid/solid electron transfer in catalysis, energy conversion processes, photocatalysis, water splitting, and so on. 


\section{ASSOCIATED CONTENT}

\section{S Supporting Information}

The Supporting Information is available free of charge on the ACS Publications website at DOI: 10.1021/acs.jpcc.7b07898.

Preparation of $\mathrm{PB}$ (pictures of the starting solution $\mathrm{K}_{3}\left[\mathrm{Fe}(\mathrm{CN})_{6}\right]$ and the final solution $\left.\mathrm{KFe}^{\mathrm{III}}\left[\mathrm{Fe}^{\mathrm{II}}(\mathrm{CN})_{6}\right]\right)$; Raman and SEM of "as-grown" $\mathrm{Gr}$ on $\mathrm{Cu}$ foil; LFM calculation of $\mathrm{PB}$ precursors $\left(\mathrm{FeCl}_{2}\right.$ and $\mathrm{K}_{3}\left[\mathrm{Fe}(\mathrm{CN})_{6}\right]$ ) and $\mathrm{PB}$ components; Raman spectra of $\mathrm{G}$ and $2 \mathrm{D}$ peaks of GNBs and a dry film of PB (PDF)

\section{AUTHOR INFORMATION}

\section{Corresponding Authors}

*E-mail: nappini@iom.cnr.it.

*E-mail: magnano@iom.cnr.it.

\section{ORCID}

Silvia Nappini: 0000-0002-4944-5487

Marco Lazzarino: 0000-0003-1077-6569

Frank.M. F. De Groot: 0000-0002-1340-2186

Coskun Kocabas: 0000-0003-0831-5552

\section{Present Addresses}

"I CERIC-ERIC (Central European Research Infrastructure Consortium), S.S. Fourteen $\mathrm{Km}$ 163.5, 34149 Basovizza, Trieste, Italy.

$\square$ Elettra-Sincrotrone Trieste S.C.p.A, S.S. Fourteen Km 163.5, 34149 Basovizza, Trieste, Italy.

\section{Author Contributions}

S.N. and E.M. planned and executed electron spectroscopy experiments and evaluated the data. S.N. drafted the manuscript. E.M. actively participated in planning the manuscript. S.N. and A.M. prepared PB solutions. A.M. prepared GNBs filled with liquid and helped with data acquisition. F.D.G actively helped in ligand field multiplet analysis. D.N. executed Raman characterization and analysis. M.L. and S.D.Z. gave general advisory and actively participated in planning the experiments. C.K. and O.B. provided the Gr layers grown on $\mathrm{Cu}$ foils. All authors have given approval to the final version of the manuscript.

\section{Notes}

The authors declare no competing financial interest.

\section{ACKNOWLEDGMENTS}

This work was supported by CNR and the Italian Ministry of Education MIUR through the national grants FIRB Futuro in Ricerca 2012 RBFR128BEC "Beyond graphene: Tailored Clayers for novel catalytic materials and green chemistry", progetto premiale ABNANOTECH and FIRB RBAP11ETKA_003. We are thankful to Dr. Federica Bondino for constructive feedback on the work. The technical support of Federico Salvador and Paolo Bertoch is acknowledged.

\section{ABBREVIATIONS}

$\mathrm{Gr}$, graphene; GNB, graphene nanobubble; $\mathrm{PB}$, Prussian blue; PW, Prussian white; XPS, X-ray photoemission spectroscopy; XAS, X-ray absorption spectroscopy; AFM, atomic force microscopy; SEM, scanning electron microscopy; UHV, ultrahigh vacuum; $\mathrm{BE}$, binding energy; TEY, total electron yield; CVD, chemical vapor deposition

\section{REFERENCES}

(1) Yamamoto, T.; Saso, N.; Umemura, Y.; Einaga, Y. Photoreduction of Prussian Blue Intercalated into Titania Nanosheet Ultrathin Films. J. Am. Chem. Soc. 2009, 131, 13196-13197.

(2) Aguilà, D.; Prado, Y.; Koumousi, E. S.; Mathonière, C.; Clérac, R. Switchable $\mathrm{Fe} / \mathrm{Co}$ Prussian Blue Networks and Molecular Analogues. Chem. Soc. Rev. 2016, 45, 203-224.

(3) Itaya, K.; Uchida, I.; Neff, V. D. Electrochemistry of Polynuclear Transition Metal Cyanides: Prussian Blue and Its Analogues. Acc. Chem. Res. 1986, 19, 162-168.

(4) Risch, M.; Stoerzinger, K. A.; Regier, T. Z.; Peak, D.; Sayed, S. Y.; Shao-Horn, Y. Reversibility of Ferri-/Ferrocyanide Redox during Operando Soft X-Ray Spectroscopy. J. Phys. Chem. C 2015, 119, 18903-18910.

(5) Neff, V. D. Some Performance Characteristics of a Prussian Blue Battery. J. Electrochem. Soc. 1985, 132, 1382-1384.

(6) Wang, L.; Song, J.; Qiao, R.; Wray, L. A.; Hossain, M. A.; Chuang, Y.-D.; Yang, W.; Lu, Y.; Evans, D.; Lee, J.-J.; et al. Rhombohedral Prussian White as Cathode for Rechargeable Sodium-Ion Batteries. J. Am. Chem. Soc. 2015, 137, 2548-2554.

(7) Malinauskas, A.; Ruzgas, T.; Gorton, L. Electrochemical Study of the Redox Dyes Nile Blue and Toluidine Blue Adsorbed on Graphite and Zirconium Phosphate Modified Graphite. J. Electroanal. Chem. 2000, 484, 55-63.

(8) Ricci, F.; Palleschi, G. Sensor and Biosensor Preparation, Optimisation and Applications of Prussian Blue Modified Electrodes. Biosens. Bioelectron. 2005, 21, 389-407.

(9) Ricci, F.; Gonçalves, C.; Amine, A.; Gorton, L.; Palleschi, G.; Moscone, D. Electroanalytical Study of Prussian Blue Modified Glassy Carbon Paste Electrodes. Electroanalysis 2003, 15, 1204-1211.

(10) Gervais, C.; Languille, M.-A.; Réguer, S.; Gillet, M.; Pelletier, S.; Garnier, C.; Vicenzi, E. P.; Bertrand, L. Why Does Prussian Blue Fade? Understanding the Role(s) of the Substrate. J. Anal. At. Spectrom. 2013, 28, 1600-1609.

(11) Samain, L.; Gilbert, B.; Grandjean, F.; Long, G. J.; Strivay, D. Redox Reactions in Prussian Blue Containing Paint Layers as a Result of Light Exposure. J. Anal. At. Spectrom. 2013, 28, 524-535.

(12) Fading and Colour Change of Prussian Blue: Methods of Manufacture and the Influence of Extenders, Technical Bulletin, National Gallery, London https://www.nationalgallery.org.uk/technicalbulletin/kirby_saunders2004 (accessed Jan 10, 2017).

(13) Itaya, K.; Shibayama, K.; Akahoshi, H.; Toshima, S. Prussianblue-modified Electrodes: An Application for a Stable Electrochromic Display Device. J. Appl. Phys. 1982, 53, 804-805.

(14) Karyakin, A. A. Prussian Blue and Its Analogues: Electrochemistry and Analytical Applications. Electroanalysis 2001, 13, 813819.

(15) Agrisuelas, J.; Bueno, P. R.; Ferreira, F. F.; Gabrielli, C.; GarcíaJareño, J. J.; Gimenez-Romero, D.; Perrot, H.; Vicente, F. Electronic Perspective on the Electrochemistry of Prussian Blue Films. J. Electrochem. Soc. 2009, 156, P74-P80.

(16) Sato, O.; Iyoda, T.; Fujishima, A.; Hashimoto, K. Photoinduced Magnetization of a Cobalt-Iron Cyanide. Science 1996, 272, 704-705.

(17) Escax, V.; Bleuzen, A.; Cartier Dit Moulin, C.; Villain, F.; Goujon, A.; Varret, F.; Verdaguer, M. Photoinduced Ferrimagnetic Systems in Prussian Blue Analogues C $(\mathrm{I}) \mathrm{XCo} 4[\mathrm{Fe}(\mathrm{CN}) 6]$ y $(\mathrm{C}(\mathrm{I})=$ Alkali Cation). 3. Control of the Photo- and Thermally Induced Electron Transfer by the $\left[\mathrm{Fe}(\mathrm{CN})_{6}\right]$ Vacancies in Cesium Derivatives. J. Am. Chem. Soc. 2001, 123, 12536-12543.

(18) Taguchi, M.; Yagi, I.; Nakagawa, M.; Iyoda, T.; Einaga, Y. Photocontrolled Magnetization of CdS-Modified Prussian Blue Nanoparticles. J. Am. Chem. Soc. 2006, 128, 10978-10982.

(19) Jiang, G.; Lin, Z.; Chen, C.; Zhu, L.; Chang, Q.; Wang, N.; Wei, W.; Tang, H. TiO2 Nanoparticles Assembled on Graphene Oxide Nanosheets with High Photocatalytic Activity for Removal of Pollutants. Carbon 2011, 49, 2693-2701.

(20) Fujishima, A.; Zhang, X.; Tryk, D. A. Heterogeneous Photocatalysis: From Water Photolysis to Applications in Environmental Cleanup. Int. J. Hydrogen Energy 2007, 32, 2664-2672. 
(21) Zhang, X.; Song, L.; Zeng, X.; Li, M. Effects of Electron Donors on the $\mathrm{TiO}_{2}$ Photocatalytic Reduction of Heavy Metal Ions under Visible Light. Energy Procedia 2012, 17, 422-428.

(22) Lichterman, M. F.; Hu, S.; Richter, M. H.; Crumlin, E. J.; Axnanda, S.; Favaro, M.; Drisdell, W.; Hussain, Z.; Mayer, T.; Brunschwig, B. S.; et al. Direct Observation of the Energetics at a Semiconductor/Liquid Junction by Operando X-Ray Photoelectron Spectroscopy. Energy Environ. Sci. 2015, 8, 2409-2416.

(23) Lu, Y.-C.; Crumlin, E. J.; Veith, G. M.; Harding, J. R.; Mutoro, E.; Baggetto, L.; Dudney, N. J.; Liu, Z.; Shao-Horn, Y. In Situ Ambient Pressure X-Ray Photoelectron Spectroscopy Studies of LithiumOxygen Redox Reactions. Sci. Rep. 2012, 2, 715.

(24) Axnanda, S.; Crumlin, E. J.; Mao, B.; Rani, S.; Chang, R.; Karlsson, P. G.; Edwards, M. O. M.; Lundqvist, M.; Moberg, R.; Ross, P.; Hussain, Z.; Liu, Z.; et al. Using "Tender” X-ray Ambient Pressure X-ray Photoelectron Spectroscopy as A Direct Probe of Solid-Liquid Interface. Sci. Rep. 2015, 5, 9788.

(25) Favaro, M.; Drisdell, W. S.; Marcus, M. A.; Gregoire, J. M.; Crumlin, E. J.; Haber, J. A.; Yano, J. An Operando Investigation of $(\mathrm{Ni}-\mathrm{Fe}-\mathrm{Co}-\mathrm{Ce}) \mathrm{Ox}$ System as Highly Efficient Electrocatalyst for Oxygen Evolution Reaction. ACS Catal. 2017, 7, 1248-1258.

(26) Favaro, M.; Yang, J.; Nappini, S.; Magnano, E.; Toma, F. M.; Crumlin, E. J.; Yano, J.; Sharp, I. D. Understanding the Oxygen Evolution Reaction Mechanism on CoOx Using Operando AmbientPressure X-Ray Photoelectron Spectroscopy. J. Am. Chem. Soc. 2017, 139, 8960-8970.

(27) Kolmakov, A.; Dikin, D. A.; Cote, L. J.; Huang, J.; Abyaneh, M. K.; Amati, M.; Gregoratti, L.; Günther, S.; Kiskinova, M. Graphene Oxide Windows for in Situ Environmental Cell Photoelectron Spectroscopy. Nat. Nanotechnol. 2011, 6, 651-657.

(28) Kraus, J.; Reichelt, R.; Günther, S.; Gregoratti, L.; Amati, M.; Kiskinova, M.; Yulaev, A.; Vlassiouk, I.; Kolmakov, A. Photoelectron Spectroscopy of Wet and Gaseous Samples through Graphene Membranes. Nanoscale 2014, 6, 14394-14403.

(29) Yulaev, A.; Guo, H.; Strelcov, E.; Chen, L.; Vlassiouk, I.; Kolmakov, A. Graphene Microcapsule Arrays for Combinatorial Electron Microscopy and Spectroscopy in Liquids. ACS Appl. Mater. Interfaces 2017, 9, 26492-26502.

(30) Guo, J.; Tong, T.; Svec, L.; Go, J.; Dong, C.; Chiou, J.-W. Soft-xRay Spectroscopy Experiment of Liquids. J. Vac. Sci. Technol., A 2007, $25,1231-1233$.

(31) Bora, D. K.; Glans, P.-A.; Pepper, J.; Liu, Y.-S.; Du, C.; Wang, D.; Guo, J.-H. An Ultra-High Vacuum Electrochemical Flow Cell for in Situ/Operando Soft X-Ray Spectroscopy Study. Rev. Sci. Instrum. 2014, 85, 043106.

(32) Guo, H.; Strelcov, E.; Yulaev, A.; Wang, J.; Appathurai, N.; Urquhart, S.; Vinson, J.; Sahu, S.; Zwolak, M.; Kolmakov, A. Enabling Photoemission Electron Microscopy in Liquids via Graphene-Capped Microchannel Arrays. Nano Lett. 2017, 17, 1034-1041.

(33) Yuk, J. M.; Park, J.; Ercius, P.; Kim, K.; Hellebusch, D. J.; Crommie, M. F.; Lee, J. Y.; Zettl, A.; Alivisatos, A. P. High-Resolution EM of Colloidal Nanocrystal Growth Using Graphene Liquid Cells. Science 2012, 336, 61-64.

(34) Wang, C.; Qiao, Q.; Shokuhfar, T.; Klie, R. F. High-Resolution Electron Microscopy and Spectroscopy of Ferritin in Biocompatible Graphene Liquid Cells and Graphene Sandwiches. Adv. Mater. 2014, 26, 3410-3414.

(35) Nappini, S.; Matruglio, A.; Naumenko, D.; Zilio, S. D.; Bondino, F.; Lazzarino, M.; Magnano, E. Graphene Nanobubbles on $\mathrm{TiO}_{2}$ for in-Operando Electron Spectroscopy of Liquid-Phase Chemistry. Nanoscale 2017, 9, 4456-4466.

(36) Kolmakov, A.; Gregoratti, L.; Kiskinova, M.; Günther, S. Recent Approaches for Bridging the Pressure Gap in Photoelectron Microspectroscopy. Top. Catal. 2016, 59, 448-468.

(37) Kraus, J.; Böbel, M.; Günther, S. Suppressing Graphene Nucleation during CVD on Polycrystalline $\mathrm{Cu}$ by Controlling the Carbon Content of the Support Foils. Carbon 2016, 96, 153-165.

(38) Martyanov, I. N.; Klabunde, K. J. Photocatalytic Purification of Water and Air over Nanoparticulate $\mathrm{TiO}_{2}$. In Nanoscale Materials in
Chemistry; Klabunde, K. J., Richards, R. M., Eds.; John Wiley \& Sons, Inc.: New York, 2009; pp 579-603.

(39) Šuligoj, A.; Štangar, U. L.; Tušar, N. N. Photocatalytic AirCleaning Using $\mathrm{TiO}_{2}$ Nanoparticles in Porous Silica Substrate. Chem. Pap. 2014, 68, 1265-1272.

(40) Favaro, M.; Leonardi, S.; Valero-Vidal, C.; Nappini, S.; Hanzlik, M.; Agnoli, S.; Kunze-Liebhäuser, J.; Granozzi, G. Carbon Doping: InSitu Carbon Doping of TiO2 Nanotubes Via Anodization in Graphene Oxide Quantum Dot Containing Electrolyte and Carburization to TiOxCy Nanotubes. Adv. Mater. Interfaces 2015, 2, 1400462.

(41) Li, L.; Yan, J.; Wang, T.; Zhao, Z.-J.; Zhang, J.; Gong, J.; Guan, N. Sub-10 Nm Rutile Titanium Dioxide Nanoparticles for Efficient Visible-Light-Driven Photocatalytic Hydrogen Production. Nat. Commun. 2015, 6, 5881.

(42) Yang, L.; Zhang, M.; Shi, S.; Lv, J.; Song, X.; He, G.; Sun, Z. Effect of Annealing Temperature on Wettability of TiO2 Nanotube Array Films. Nanoscale Res. Lett. 2014, 9, 621.

(43) Zhang, K.-X.; Wang, W.; Hou, J.-L.; Zhao, J.-H.; Zhang, Y.; Fang, Y.-C. Oxygen Plasma Induced Hydrophilicity of TiO2 Thin Films. Vacuum 2011, 85, 990-993.

(44) Jung, C.-K.; Bae, I.-S.; Song, Y.-H.; Boo, J.-H. Plasma Surface Modification of $\mathrm{TiO} 2$ Photocatalysts for Improvement of Catalytic Efficiency. Surf. Coat. Technol. 2005, 200, 1320-1324.

(45) Tissot, H.; Gallet, J.-J.; Bournel, F.; Olivieri, G.; Silly, M. G.; Sirotti, F.; Boucly, A.; Rochet, F. The Electronic Structure of Saturated $\mathrm{NaCl}$ and $\mathrm{NaI}$ Solutions in Contact with a Gold Substrate. Top. Catal. 2016, 59, 605-620.

(46) Ketteler, G.; Yamamoto, S.; Bluhm, H.; Andersson, K.; Starr, D. E.; Ogletree, D. F.; Ogasawara, H.; Nilsson, A.; Salmeron, M. The Nature of Water Nucleation Sites on $\mathrm{TiO} 2(110)$ Surfaces Revealed by Ambient Pressure X-Ray Photoelectron Spectroscopy. J. Phys. Chem. C 2007, 111, 8278-8282.

(47) Yang, D.; Velamakanni, A.; Bozoklu, G.; Park, S.; Stoller, M.; Piner, R. D.; Stankovich, S.; Jung, I.; Field, D. A.; Ventrice, C. A., Jr.; et al. Chemical Analysis of Graphene Oxide Films after Heat and Chemical Treatments by X-Ray Photoelectron and Micro-Raman Spectroscopy. Carbon 2009, 47, 145-152.

(48) Chu, D.; Younis, A.; Li, S. Direct Growth of TiO 2 Nanotubes on Transparent Substrates and Their Resistive Switching Characteristics. J. Phys. D: Appl. Phys. 2012, 45, 355306.

(49) Xing, M.; Shen, F.; Qiu, B.; Zhang, J. Highly-Dispersed BoronDoped Graphene Nanosheets Loaded with $\mathrm{TiO}_{2}$ Nanoparticles for Enhancing $\mathrm{CO}_{2}$ Photoreduction. Sci. Rep. 2015, 4, 6341.

(50) Jia, Y.; Gong, X.; Peng, P.; Wang, Z.; Tian, Z.; Ren, L.; Fu, Y.; Zhang, H. Toward High Carrier Mobility and Low Contact Resistance: Laser Cleaning of PMMA Residues on Graphene Surfaces. Nano-Micro Lett. 2016, 8, 336-346.

(51) Banerjee, S.; Dionysiou, D. D.; Pillai, S. C. Self-Cleaning Applications of $\mathrm{TiO}_{2}$ by Photo-Induced Hydrophilicity and Photocatalysis. Appl. Catal., B 2015, 176, 396-428.

(52) Hocking, R. K.; Wasinger, E. C.; de Groot, F. M. F.; Hodgson, K. O.; Hedman, B.; Solomon, E. I. Fe L-Edge XAS Studies of $\mathrm{K} 4[\mathrm{Fe}(\mathrm{CN}) 6]$ and $\mathrm{K} 3[\mathrm{Fe}(\mathrm{CN}) 6]$ : A Direct Probe of Back-Bonding. J. Am. Chem. Soc. 2006, 128, 10442-10451.

(53) Gervais, C.; Languille, M.-A.; Moretti, G.; Réguer, S. X-Ray Photochemistry of Prussian Blue Cellulosic Materials: Evidence for a Substrate-Mediated Redox Process. Langmuir 2015, 31, 8168-8175.

(54) Dung, D.; Ramsden, J.; Graetzel, M. Dynamics of Interfacial Electron-Transfer Processes in Colloidal Semiconductor Systems. J. Am. Chem. Soc. 1982, 104, 2977-2985.

(55) Ferrari, A. C. Raman Spectroscopy of Graphene and Graphite: Disorder, Electron-phonon Coupling, Doping and Nonadiabatic Effects. Solid State Commun. 2007, 143, 47-57.

(56) Ferrari, A. C.; Basko, D. M. Raman Spectroscopy as a Versatile Tool for Studying the Properties of Graphene. Nat. Nanotechnol. 2013, $8,235-246$

(57) Barsan, M. M.; Butler, I. S.; Fitzpatrick, J.; Gilson, D. F. R. HighPressure Studies of the Micro-Raman Spectra of Iron Cyanide Complexes: Prussian Blue $(\mathrm{Fe} 4[\mathrm{Fe}(\mathrm{CN}) 6] 3)$, Potassium Ferricyanide 
$(\mathrm{K} 3[\mathrm{Fe}(\mathrm{CN}) 6])$, and Sodium Nitroprusside $(\mathrm{Na} 2[\mathrm{Fe}(\mathrm{CN}) 5(\mathrm{NO})]$. 2H2O). J. Raman Spectrosc. 2011, 42, 1820-1824.

(58) Salihoglu, O.; Balci, S.; Kocabas, C. Plasmon-Polaritons on Graphene-Metal Surface and Their Use in Biosensors. Appl. Phys. Lett. 2012, 100, 213110.

(59) Li, X.; Cai, W.; An, J.; Kim, S.; Nah, J.; Yang, D.; Piner, R.; Velamakanni, A.; Jung, I.; Tutuc, E.; et al. Large-Area Synthesis of High-Quality and Uniform Graphene Films on Copper Foils. Science 2009, 324, 1312-1314.

(60) Zangrando, M.; Finazzi, M.; Paolucci, G.; Comelli, G.; Diviacco, B.; Walker, R. P.; Cocco, D.; Parmigiani, F. BACH, the Beamline for Advanced Dichroic and Scattering Experiments at ELETTRA. Rev. Sci. Instrum. 2001, 72, 1313-1319.

(61) Zangrando, M.; Zacchigna, M.; Finazzi, M.; Cocco, D.; Rochow, R; Parmigiani, F. Polarized High-Brilliance and High-Resolution Soft $\mathrm{X}$-ray Source at ELETTRA: The Performance of Beamline BACH. Rev. Sci. Instrum. 2004, 75, 31-36.

(62) Drera, G.; Salvinelli, G.; Åhlund, J.; Karlsson, P. G.; Wannberg, B.; Magnano, E.; Nappini, S.; Sangaletti, L. Transmission Function Calibration of an Angular Resolved Analyzer for X-Ray Photoemission Spectroscopy: Theory vs Experiment. J. Electron Spectrosc. Relat. Phenom. 2014, 195, 109-116.

(63) Thole, B. T.; van der Laan, G.; Fuggle, J. C.; Sawatzky, G. A.; Karnatak, R. C.; Esteva, J.-M. 3d. Phys. Rev. B: Condens. Matter Mater. Phys. 1985, 32, 5107-5118.

(64) Cowan, R. D. The Theory of Atomic Structure and Spectra; University of California Press: Berkeley, CA, 1981.

(65) Stavitski, E.; de Groot, F. M. F. The CTM4XAS Program for EELS and XAS Spectral Shape Analysis of Transition Metal L Edges. Micron 2010, 41, 687-694. 